\title{
Conflict in Technical Assistance
}

\author{
by Percy Selwyn*
}

As all the books say, the function of technical assistance is to fill a resource gap, by providing people with particular skills - either to deal with ad hoc problems, or to meet a continuing need which will eventually be filled by local people. But to think of technical assistance people in this abstract way as a "resource" can be misleading. They are not a more or less uniform resource like capital aid (even tied capital aid - an American truck isn't all that different from a British truck or a German truck) oi food aid. Technical assistance experts are people that is, individuals with their own national and social backgrounds, their own prejudices, their own career structures, and their own attitudes to the jobs they are asked to do. Some of these individual characteristics may be helpful; others may be damaging, but some or all of them will conflict with the optimum use of the technical assistance expert as a "resource".

Some of these drawbacks are obvious and well known. There is, however, one potential source of conflict which has, I believe, been insufficiently considered. This is the conflict between the time-scale of the visiting expert and the time-scale of the problems with which he is supposed to deal. Most technical assistance experts are appointed for periods up to two years. UN appointments are normally for one year in the first instance, but are frequently renewed. But whatever the period, the expert normally has a discrete time horizon at the end of which his concern with the particular country will end. He will normally accept that the "problem" (whatever this might be) will not go away merely because he does, but he must still be influenced in various ways by this presence of a finite time horizon.

The first (and in many administrations the most frequent) conflict will be between the desire of the expert to "get 
something done" during the period of his appointment, and local politicians and administrators who have lived with the problems for many years and who expect to continue to live with them for many more years. Sometimes this may reflect realism; sometimes mere inertia. In either event, there will be a conflict between the time-scale of the expert and that of the administration. In extreme cases, I have seen this lead experts to near-paranoiac states of mind. In a situation of this kind it is useless to apportion blame. The administration may be at fault for lacking a sense of urgency; the expert may be at fault for failure to see his own role in the longer-term context of the country's history. But wherever the fault lies, the effectiveness of the expert as a resource will be reduced.

The type of advice given by the expert will be influenced by this time horizon. He may have an unconscious bias in favour of projects with a short - or at any rate an easily foreseeable - pay-off, at the expense of longer-term policies and programmes. This seems to be particularly the case with visiting expert missions, who may feel impelled to suggest some self-contained projects with a clearly defined time-scale merely in order to justify their own existence. This particular prejudice may, however, be welcomed by governments who find it easier to think of development in terms of specific projects (which do not involve the more fundamental and difficult policy and organisational changes which are really needed), and are therefore happy to cooperate with the visiting expert who suggests such an approach.

There is one particular field where the time horizon of the visiting expert may be of substantial importance. Much of the argument about public corporations in developing countries has tended to be carried on at an ideological level - as a question of principle. But one central issue is the nature and attitudes of the managers of these corpor ations. Many such corporations are managed by expatriates brought in under technical assistance arrangements. Such people, if they are any good, are usually in mid-career in other occupations. They may be concerned to make a success of the operation to which they are assigned, but the criteria by which they judge "success" will be overwhelmingly influenced by their time horizon.

Two types of public corporation are of central importance in this context - development corporations (charged with a general responsibility for attracting or promoting investment) and development banks. We are all familiar now with the fact that managers of large modern corporations may be 
concerned more with growth than with profitability. Similar1y the development corporation manager with a two-year contract may consider that his success will be judged more by the amount of investment he promotes or the number of enterprises he gets off the ground than with quality of the investment, the benefits which it produces for the local economy, or the fate of the enterprises in five years time. Such managers may indeed resent any suggestion that their investment proposals should be subject to some overriding criterion of national benefit, and may quite seriously regard suggestions of this kind as sabotage of the development effort.

Similarly the "success" of a development bank - at least in the short run - may be judged on the basis of the level of loans made and the proportion of such loans which are repaid. But if a development bank wishes to expand its business in the short run, it will usually find that the easiest path is to lend to the modern and successful sectors of the economy. The bank may therefore help to accentuate the dualism of the economy. So in a sugar economy the bank will mostly lend to the sugar industry; in a mineral economy to the mining industry. Everywhere banks will support the established rather than the struggling sectors of the economy. This tendency may also be confirmed if the manager is unduly influenced by traditional "banking" views about security, but even without such prejudices the time horizon within which the manager is working will push him towards the kind of business which promises the most rapid and risk-free expansion.

There is no simple solution to this problem of limited time horizons, but two possible approaches might be considered.

First, there is the possibility that technical assistance appointments should be for longer periods. This creates obvious difficulties. A foreign expert who works in a country for a long time (as do many people working under OSAS arrangements) may become too closely involved in the working of the administration. He may become part of a byzantine struggle for power and influence, or may in other ways lose whatever independence he had. He may, consciously or unconsciously, block the training and promotion of local personnel who might take his job. Moreover, he may come to accept the time scale of the host government, even where this is clearly inappropriate to the needs of the country. To do so will certainly lessen conflict, but may not increase effectiveness. 
Secondly, there may be a role for better training and briefing of technical assistance experts. It must not be assumed that, merely because the expert knows all about his own subject, he will necessarily be effective in his job. If experts are made more aware of the longer term problems of the countries in which they are to operate, there is some possibility that they will see their own limited operation in a broader context, and will be less influenced by their own narrow time horizons. The difficulty is who is to do the briefing. Ideally it should be the host government, but they may be unaware of the problem, and may indeed have little idea of the role they expect the expert to play. Universities or development institutes in host countries might also help, but their services will not be used unless there is a wider awareness of the nature of the problem. We are faced with a situation somewhat akin to that of university teachers. It is assumed that somebody who knows his subject is capable of teaching it, and that no special training is needed in the art of teaching - this against all experience of anybody who has had to sit through university lectures. But the problem cannot be tackled until there is a general awareness of it.

Lastly, it is possible that some countries have only a very limited absorptive capacity for technical assistance merely because the gap between the time horizon of the expert and that of the local administration is impossibly wide. This may well be one of the insoluble problems in development aid. 